\title{
Gisbert, M.; Esteve-González, V. y Lázaro, J.L. (Eds.) (2019). ¿Cómo abordar la educación del futuro? Conceptualización, desarrollo y evaluación desde la competencia digital docente. Barcelona: Octaedro (Colección Universidad). 241 pág. ISBN: 978-84-17219-88-8
}

Bajo el título ¿Cómo abordar la educación del futuro? Conceptualización, desarrollo y evaluación desde la competencia digital docente se presentan, desde distintos enfoques, aspectos relativos a la competencia digital docente (CDD) y el modo en que esta interviene en los espacios formativos universitarios actuales. En 14 capítulos, Gisbert, Esteve-González y Lázaro, junto a 35 expertos, ahondan en su descripción, además de en la importancia de su despliegue en la formación de maestros y en el ejercicio de la profesión docente.

La competencia digital (CD) se ha planteado, en las últimas décadas, como un conjunto de habilidades a las que debe responder el ciudadano para poder participar con responsabilidad y éxito en la sociedad de la información. Consecuentemente, la realidad educativa también se ha visto afectada por esta perspectiva incorporando ordenadores, aplicaciones, tabletas, etc. en las aulas, lo que ha llevado a condicionar las destrezas tecnológicas del profesorado en su entorno laboral. De aquí que se desprenda una nueva noción, la de CDD, entendida como una capacidad que va más allá del dominio técnico y que comprende acciones paralelas relacionadas con el uso de estos dispositivos desde una vertiente más pedagógica y didáctica.

Frente a esta realidad, el libro publicado por Octaedro trata de ofrecer un panorama completo en relación a la CDD que se desprende del trabajo realizado por el grupo de investigación ARGET en distintos proyectos: TEL3D, SIMUL@, SIMUL@B, COMDID y Disseny i validació d'una estratègia per a l'avaluació i certificació de la competència digital docent. Se trata de investigaciones que han permitido conceptualizar la alfabetización digital y desarrollar estrategias didáctico-metodológicas, diseños de escenarios digitales, herramientas evaluativas e intervenciones en el aula de la formación docente.

Para el desarrollo de este volumen se contemplan los principios de instituciones como la UNESCO con los estándares de competencias en TIC para docentes (2008), la ISTE a través de National educational technology standards for teachers (2009), la Comisión Europea en el DigComp: A Framework for Developing and Understanding Digital Competence in Europe (2013) o la Generalitat de Catalunya con Teachers' Digital Competence in Catalonia (2018). Aunque también se ponen en relieve las estadísticas sobre oportunidades de acceso y aprovechamiento de las TIC de la International telecommunication Union (2017).

En relación a la estructura de la propuesta, esta se organiza en 14 capítulos que se distribuyen en 4 bloques según un enfoque conceptual, metodológico, de desarrollo del proceso formativo e internacional. Así pues, en los primeros capítulos (1-4) se expone el concepto de CDD y se contextualiza en escenarios virtuales, como son los Entornos 3D, para, posteriormente, evidenciar la necesidad de formar en esta competencia desde una perspectiva integradora tanto en la práctica de estudio como en 
el ámbito profesional. Se continúa con propuestas metodológicas (cap. 5-8) que permiten desarrollar la $C D D$, gamificación o laboratorios 3D (simulaciones), pero también evaluar y mejorar las prácticas formativas en torno a la competencia mencionada. A continuación (cap. 9-11), se recupera, por un lado, la comunicación como el elemento que permite materializar las ideas en los procesos de aprendizaje virtuales $y$, por otro, el aprendizaje servicio como método que reporta beneficios a todos los participantes de la comunidad educativa. Se destaca, en este punto, la integración de la acción social y solidaria efectuada en la Universitat Rovira i Virgili desde el 2012. Con ello, se pone en relieve qué y cómo se debe evaluar en los entornos 3D, espacios en los que intervienen los aspectos anteriores. Seguidamente (cap. 12-13), se señalan las brechas que existen en el acceso y uso de las TIC entre países de América Latina y estos respecto datos internacionales; también los desafíos en relación al desarrollo de la competencia digital estudiantil. Finalmente (cap. 14), se pone en entredicho que la enseñanza en las TIC deba relegarse a la formación continua y casi a la voluntariedad del profesorado, lo que lleva a reflexionar sobre el compromiso que cabe adoptar desde la sociedad y comunidades educativas para asegurar la CDD como un elemento íntegro de todos los planes de estudio.

En este sentido, las contribuciones realizadas por los editores y el resto de expertos se convierten en una herramienta que guía en la comprensión, el diseño y la intervención de acciones desarrolladoras de la CDD en el contexto universitario. No obstante, siguen siendo de utilidad para otros agentes que participen en la formación, bien sean instituciones, bien docentes en activo o figuras del ámbito no formal e informal que quieran fomentar estos conceptos.

Blanca Carrera González Universitat d'Andorra 